\title{
A Survey on Underwater Acoustic Sensor Networks: Perspectives on Protocol Design for Signaling, MAC and Routing
}

\author{
Mohammad Sharif-Yazd1, Mohammad Reza Khosravi², Mohammad Kazem Moghimi ${ }^{*}$ \\ ${ }^{1}$ Department of Electrical Engineering, Yazd Branch, Islamic Azad University, Yazd, Iran \\ ${ }^{2}$ Department of Electrical and Electronic Engineering, Shiraz University of Technology, Shiraz, Iran \\ ${ }^{3}$ Department of Electrical Engineering, Najafabad Branch, Islamic Azad University, Najafabad, Iran \\ Email: ${ }^{\star}$ moghimi.kazem@sel.iaun.ac.ir
}

How to cite this paper: Sharif-Yazd, M., Khosravi, M.R. and Moghimi, M.K. (2017) A Survey on Underwater Acoustic Sensor Networks: Perspectives on Protocol Design for Signaling, MAC and Routing. Journal of Computer and Communications, 5, 12-23. https://doi.org/10.4236/jcc.2017.55002

Received: February 2, 2017

Accepted: March 11, 2017

Published: March 14, 2017

Copyright $\odot 2017$ by authors and Scientific Research Publishing Inc. This work is licensed under the Creative Commons Attribution International License (CC BY 4.0).

http://creativecommons.org/licenses/by/4.0/ (c) $\underset{\mathrm{EY}}{\text { (†) Open Access }}$

\begin{abstract}
Underwater acoustic sensor networks (UASNs) are often used for environmental and industrial sensing in undersea/ocean space, therefore, these networks are also named underwater wireless sensor networks (UWSNs). Underwater sensor networks are different from other sensor networks due to the acoustic channel used in their physical layer, thus we should discuss about the specific features of these underwater networks such as acoustic channel modeling and protocol design for different layers of open system interconnection (OSI) model. Each node of these networks as a sensor needs to exchange data with other nodes; however, complexity of the acoustic channel makes some challenges in practice, especially when we are designing the network protocols. Therefore based on the mentioned cases, we are going to review general issues of the design of an UASN in this paper. In this regard, we firstly describe the network architecture for a typical 3D UASN, then we review the characteristics of the acoustic channel and the corresponding challenges of it and finally, we discuss about the different layers e.g. MAC protocols, routing protocols, and signal processing for the application layer of UASNs.
\end{abstract}

\section{Keywords}

Acoustic Communications, Underwater Acoustic Sensor Networks (UASNs), Underwater Medium Access Control (Underwater MAC), Underwater Routing, Distributed Signal Processing

\section{Introduction}

Monitoring of underwater environment is very important in marine science and technology. To cover this monitoring, creating underwater sensor networks is 
essential in undersea space. Besides, these networks have many sensor nodes with wireless links to each other. The wireless networks are used for underwater applications such as monitoring under the surface of seas and oceans and different applications in military, environmental and industrial usages. For example, there is need to underwater observatory to track submarines and to identify resources of pollution. Other applications can be noted are undersea monitoring for discovering the natural resources such as oil, gas and minerals [6]. To monitor these applications, it is necessary to have sensors in the underwater space. Since this monitoring is widely used, there are needs to be placed many of these sensors in there. Also to analyze the outputs of these sensors accurately, the sensors must be networked with each other in order to exchange information. Since establishment of a centralized network such as wired or access point-based wireless networks under the water surface especially in deep places is very expensive and in some cases is technically impossible or needs a long time, wireless networks in form of without structure (ad-hoc topology) are used. On the other hand in these new wireless networks, because the electromagnetic waves are very short-range, acoustic waves are used for communication between the sensors.

Figure 1 shows a sample 3D underwater sensor networks with hybrid architecture (some nodes are static and other nodes are mobile). Due to the high electromagnetic wave's attenuation in water, we must use acoustic waves instead of electromagnetic waves in underwater wireless networks. This issue makes new challenges related to the features of acoustic wave. The rest of this paper is as follows: at first, we review features of propagation model in acoustic channels, and then in the third section, we discuss the challenges of acoustic links in order to apply in underwater networking. Final section is allocated to conclusion.

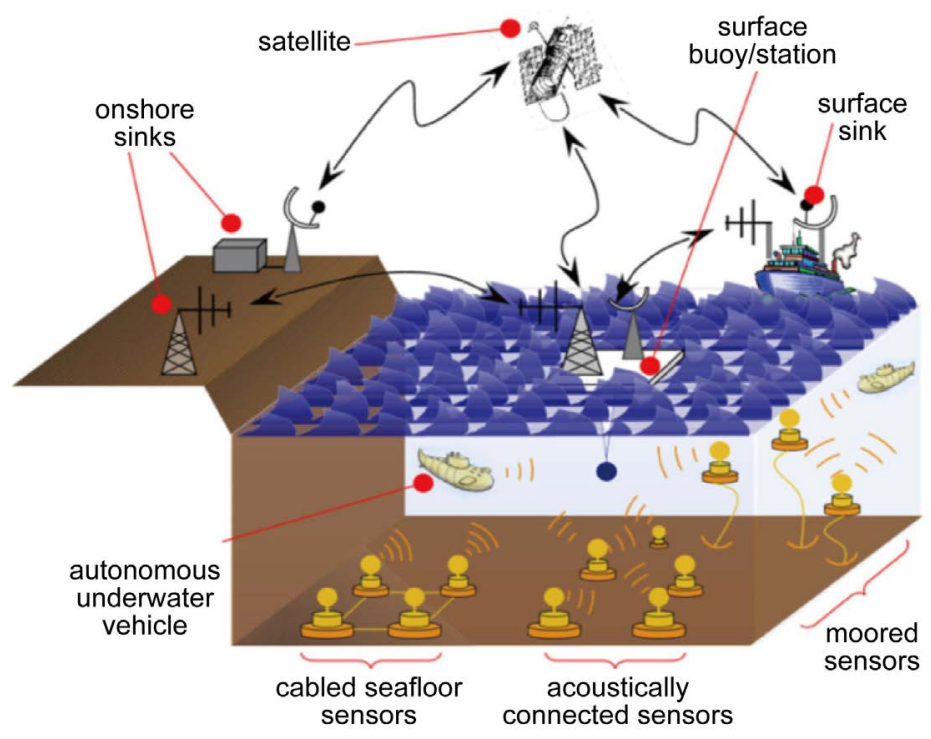

Figure 1. A typical 3D hybrid acoustic sensor network with static and mobile nodes; the network can be heterogeneous in terms of underwater space dimensions where consists of $2 \mathrm{D}$ and $3 \mathrm{D}$ sub-networks simultaneously, and additionally has mobile and static nodes (this figure has been extracted from [7]). 


\section{Propagation Model in Acoustic Channels}

The specific features of the undersea environment affect energy consumption and traffic performance of the sensor nodes and also propagation of acoustic signal in the environment. The Thorp propagation model [1] is applied to explain the acoustic channel in underwater communications. As follows, we review some main details of the channel. The acoustic channel attenuation over distance $d$ can be expressed as below (Equation (1)) where $k$ denotes the geometric spreading $(k \simeq 1.5)$. In addition, $\alpha(f)$ represents the absorption coefficient.

$$
A(d, f)=d^{k} \alpha(f)^{d}
$$

The formulation of $\alpha(f)$ is expressed by the Thorp's propagation model as Equation (2), where $\alpha(f)$ is measured in $\mathrm{dB} / \mathrm{Km}$ and $f$ is measured in $\mathrm{KHz}$. The underwater environment noise can be expressed as Equation (3).

$$
\begin{aligned}
& \alpha(f)= \begin{cases}\frac{0.11 f^{2}}{1+f^{2}}+\frac{44 f^{2}}{4100+f^{2}}+2.75 \times 10^{-4} f^{2}+0.003 & f \geq 0.4 \\
0.002+0.11 \frac{f^{2}}{1+f^{2}}+0.11 f^{2} & f<0.4\end{cases} \\
& N(f)=N_{t}(f)+N_{s}(f)+N_{w}(f)+N_{t h}(f)
\end{aligned}
$$

In Equation (3), $N_{t}(f), N_{s}(f), N_{w}(f)$ and $N_{t h}(f)$ denote different noises of the channel. $N_{t}(f)$ is caused by turbulence, $N_{s}(f)$ is by shipping movements, and also $N_{w}(f)$ and $N_{t h}(f)$ are affected by waves and thermal/ heat energy, respectively (see more details in [1]). For the acoustic signal with frequency of $f$ and propagation distance of $d$ in the underwater environment, signal to noise ratio at the receiver can be represented as the following equation.

$$
\operatorname{SNR}(f, d)=\frac{P(f)}{A(d, f) N(f)} \geq D T
$$

In above equation, $P(f)$ shows the sending power at the sender. At the receiver, if $\operatorname{SNR}(f, d)$ is not less than $D T$, the receiver can detect the received signals without error and correctly. $D T$ represents the detection threshold of the received signal. Therefore, we can dynamically set the transmission power of the sender according to the propagation distance, signal frequency and ambient control factors to decrease the consumed energy and prolong the network lifetime.

The underwater propagation velocity is a function of some things as temperature, pressure and salinity of seawater, which is written as Equation (5) [2], where $c$ shows the propagation velocity of sound in $\mathrm{m} / \mathrm{s} ; T$ shows the temperature in degree Celsius; $S$ represents the salinity in parts per thousand, and $D$ is the depth in meters. It is observable that the sound velocity has direct relationship with temperature, depth and salinity. Equation (5) is valid when the conditions are satisfied as follows: $0 \leq T \leq 30,30 \leq S \leq 40$ and $0 \leq D \leq 8000$. 


$$
\begin{aligned}
c= & 1448.96+4.591 T-5.304 \times 0.01 T^{2}+2.374 \times 0.01 T^{3}+1.340(S-35) \\
& +1.63 \times 0.1 D+1.675 \times 10^{-7} D^{2}-1.025 \times 0.01 T(S-35)-7.139 \times 10^{-13} T D^{3}
\end{aligned}
$$

\section{UASNs' Challenges}

In the previous section, we understood the specific features of an acoustic communication channel. These features create challenging issues in underwater sensor networks. In sub-sections of the current section, we review corresponding issues of different layers of UASNs from the PHY layer to application layer.

\subsection{Physical (PHY) Layer}

Table 1 shows available bandwidth for different ranges in underwater acoustic channels, in fact, the features of underwater acoustic channel have caused these outputs in practical studies. Note that this table is independent from any signaling scheme (communication modulation, coding and etc.) and also transmission power, and in fact only shows available bandwidth in Hz. Explicitly, bandwidth is depended to distance from wave source that it is known as communication range in $\mathrm{Km}$. Therefore, the bandwidth limitation is a major problem in the acoustic channels. Table 2 shows the limited data rate in different signaling techniques as another major challenge which is directly related to the bandwidth limitation. It is noticeable that in the recent years, by use of efficient signaling in the limited bandwidth, data rate (bit per second) has increments in order of 10 Kbps. This table is only obtained according to limited transmission power that is operational and allowed for the underwater environment.

Table 1. Available bandwidth for different ranges in underwater acoustic channels [5].

\begin{tabular}{ccc}
\hline Coverage & Range $(\mathrm{Km})$ & Bandwidth $(\mathrm{KHz})$ \\
\hline Very long & 1000 & Less than 1 \\
Long & $10-100$ & $2-5$ \\
Medium & $1-10$ & 10 \\
Short & $0.1-1$ & $20-50$ \\
Very short & Less than 0.1 & More than 100 \\
\hline
\end{tabular}

Table 2. Progress in digital modulation techniques for acoustic channels [4] [44]; notation (s) shows shallow waters and (d) shows deep waters.

\begin{tabular}{ccccc}
\hline Type & Year & Rate (Kbps) & Range (Km) & Bandwidth (KHz) \\
\hline FSK & 1984 & 1.2 & $3 \mathrm{~s}$ & 5 \\
FSK & 1997 & $0.6-2.4$ & $10 \mathrm{~d}-5 \mathrm{~s}$ & 5 \\
DPSK & 1997 & 20 & $1 \mathrm{~d}$ & 10 \\
QPSK & 1998 & $1.67-6.7$ & $4 \mathrm{~d}-2 \mathrm{~s}$ & $2-10$ \\
16-QAM & 2001 & 40 & $0.3 \mathrm{~s}$ & 10 \\
8-PSK & 2010 & 120 & $0.62 \mathrm{~d}$ & 80 \\
\hline
\end{tabular}


Another major problem in acoustic channels is high delay links in comparison to the electromagnetic channels which have carrier waves with speed similar to the light speed $\left(3 \times 10^{8} \mathrm{~m} / \mathrm{s}\right)$. Speed of acoustic wave in underwater space is about $1500 \mathrm{~m} / \mathrm{s}$, but it is not fixed. This low speed creates high delay and it is very effective on the network performance. Complexity of acoustic channels versus electromagnetic channels is more than two issues of low bandwidth and high delay links, so main challenges have been listed in Table 3. This table also shows reasons of each challenge briefly. Some of them are main reasons of lower bandwidth of the acoustic links and the rest of them are main reasons for low data rate (Kbps) directly [6]. Bitrate is a main factor in traffic engineering of communication networks that is effective on quality of service (QoS) in exchanging multimedia contents, such as images and videos. For achieving a comprehensive view of key challenges of this layer, see Table 4.

\subsection{MAC Protocols}

Medium access control (MAC) is an important part of data link layer (the second layer in the OSI model). Main duty of MAC is channel allocation or in the other words, bandwidth multiplexing based on multiple access techniques in networks. Hereby, MAC protocols in addition to modulation and channel coding techniques which are used in PHY layer, can be known a way for enhancing the network signaling. Of course, there are some appearances of signaling in the application layer, i.e., control of the network performance based on application layer tools and efficient signal processing techniques. Generally in wireless net-

Table 3. A brief list of the challenges in PHY layer based on the acoustic channel.

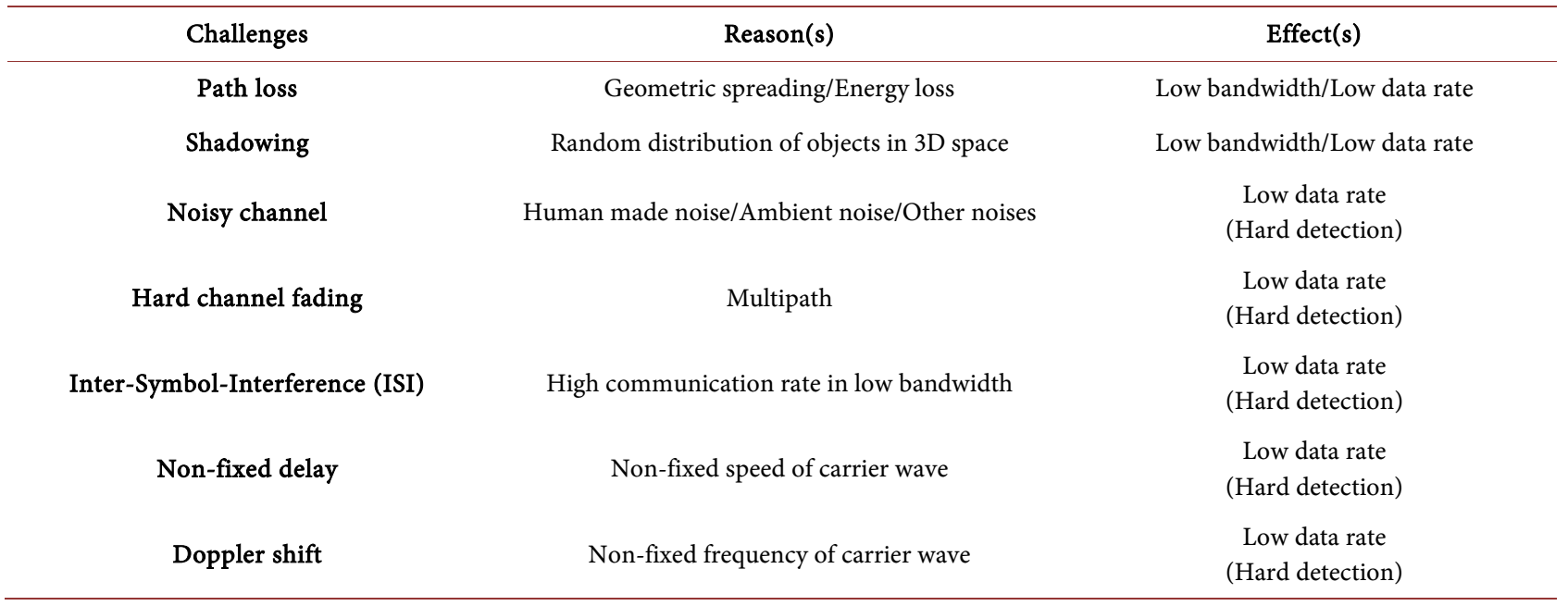

Table 4. Main concluded challenges of PHY layer.

\begin{tabular}{cccc}
\hline Effects & Intrinsic factor (Directly) & Controllable factor & Solutions \\
\hline Low bandwidth & Yes & No & Only by control of data rate \\
Low data rate & No & Yes & Efficient and high performance signaling \\
High delay & Yes (Propagation delay) & Yes (Processing delay) & Reduction of processing delay \\
\hline
\end{tabular}


works, MAC protocols are classified into two categories, contention-based techniques (random access techniques or techniques with shared channel, e.g. ALOHA, carrier sense multiple access (CSMA) and its applied versions) and channelization techniques (deterministic techniques with unshared channel, e.g. frequency division multiple access (FDMA), time division multiple access (TDMA), code division multiple access (CDMA [42]) and space division multiple access (SDMA)) [8] [9]. The low bandwidth issue of the underwater acoustic links causes that in practice, the second category often becomes unsuitable in these links, however, there are some specific cases based on channelization techniques, see more about them in [10] [11]. Assume that number of the sensor nodes is $\mathrm{N}$, then for creating an unshared channel, we have to create too large number of independent connections between all sensor nodes, therefore, the number of connections for all the network can be observed in Equation (6). When $\mathrm{N}$ becomes greater than about 50 nodes (under each volume of $3 \mathrm{D}$ space; in practice number of nodes in comparison to volume of $3 \mathrm{D}$ space affects the density of a network; where the density is depended on some variables such as number of nodes, sensing coverage, communication coverage, volume of space and maybe mobility of nodes in some cases), consequently, we need at least 1250 independent sub-channels. Therefore it is noticeable that in dense underwater networks, MAC protocols with the shared channel are more proper than the unshared channels.

$$
\begin{aligned}
& \text { Number of Independent Connections }(\mathrm{NIC})=\left(\begin{array}{c}
N \\
2
\end{array}\right)=\frac{N(N-1)}{2} \\
& \stackrel{\text { If } N=50}{\rightarrow} \quad \mathrm{NIC}=1250 \\
& \stackrel{\text { If Bitrate }=100 \mathrm{Kbps}}{\rightarrow} \quad \text { Bitrate of each channel }=\frac{100 \mathrm{Kbps}}{1250}<100 \mathrm{bps}
\end{aligned}
$$

Some of the most famous MAC protocols for the acoustic channels which all of them have often been derived based on CSMA (they are enhanced versions of CSMA with collision avoidance (CSMA/CA)), are underwater MAC/broadcasting [6], T-MAC and Tu-MAC [12] and so on.

\subsection{Routing Protocols}

Classically, design of routing protocols for terrestrial (electromagnetic) wireless sensor networks is according to path-based policy, namely, routing process selects a path with lowest cost for packet forwarding based on a computational criterion. Therefore, this type of routing protocols is named single-path routing. However, high delay of the acoustic links concurrently with mobility of the sensor nodes makes path-based routing techniques inefficient, because under any cost function, while a path (shortest path) is selected for forwarding process, variation of the network topology makes the selected path invalid very soon. Basically, three types of mobility exist in a WSN, static topology, low-speed topology and high-speed topology where two last cases are dynamic; especially when WSNs are used for underwater environment, their topology is mainly dy- 
namic, whether variation of topology is low-speed/smooth (only by external force of marine streams) or high-speed/fast (with both external and internal forces). Consequently in the recent years, design of underwater routing protocols is often based on the flooding algorithm [9]. Nowadays, flooding-based routing is widely used, although it has an intrinsic inefficiency due to the use of multi-path process. However in practice, the multi-path techniques are better than the single-path techniques in the most cases (specifically in the high-speed topology) in terms of terrific and even lifetime performance. Of course, there are some path-based protocols in this respect based on TDMA, OFDMA and so on, read more information about them in [13] [45]. Two most famous multi-path routing protocols are VBF [17] [41] and DBR [18]. Already, there are many extensions based on both, for example EE-DBR [14], D-DBR [15], EELD-DBR [16] for DBR and HH-VBF [19], AHH-VBF [3], CDZ-VBF [20], SD-VBF [6] and RC-VBF [21] for VBF. Figure 2 shows the details of basic VBF protocol as a multi-path technique. In multi-path techniques, there are several paths between the sender and the receiver which they create a redundancy for the problem of path loss in the underwater channel.

\subsection{Transport Layer}

Classic protocols of this layer are transmission control protocol (TCP) and user datagram protocol (UDP) [8] [9]. High delay of the links in UASNs is compatible with UDP, because UDP has lower processing delay than TCP, therefore it can obtain the metrics of quality of service (QoS) efficiently. A research topic for this layer is the topology control problem of wireless networks.

\subsection{Application Layer and Signal Processing}

Application layer and signal processing issues in WSNs and UASNs are so hot and new topics for the related researches. Previously, application layer of WSNs has been considered similar to the internet network and according to TCP/IP

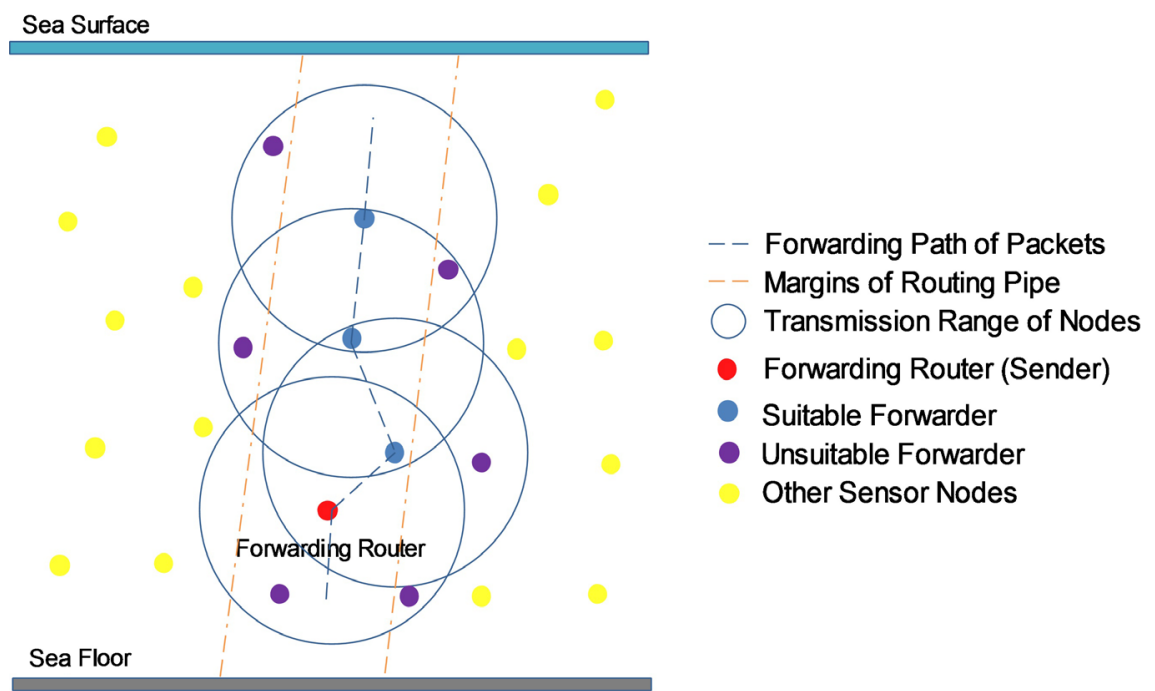

Figure 2. Schematic of VBF. 
standard (at most). However, we newly see that some studies on the application layer of WSNs are done which propose novel strategies for the specific usages of WSNs. These researches pay attention to some traffic tools of the application layer, security of the layer and signal processing algorithms related to the layer. Combination of WSNs and new topics such as internet of things, big data, and software defined networks (SDNs) are currently hot areas for researches. However, developing the mentioned cases in UASNs is completely in first steps and number of researches is limited (for example [43]), therefore, it is a good area for future researches. According to the technical progress of electronic chips in the recent years, the sensor nodes of an UASN can do data processing more than the past decades. In Figure 3, part (a) shows the integration and processing of all received data from all sensor nodes of a WSN by a final central processing unit (CPU) at the receiver side, where in this architecture, the sensor nodes are not able to do the complete processing. Part (b) shows the elements of a smart sensor which has a single-chip microprocessor, where in this second architecture, all processes on the sensed data of all sensors can be performed by themselves; in the other words, WSN operates as a distributed system with parallel processing. Some of signal processing algorithms which have already been proposed for WSNs are mainly about visual sensor networks and video communications over WSNs [23] [24] [25] [26] [27]. Therefore, the most of aspects in signal processing can be adapted with the applications related to UASNs, for example information fusion, image and video processing [28]-[40].

\subsection{Integrated Challenges and Cross-Layer Constraints}

As a final review, we integrate all challenges and constraints of UASNs in Figure 4. Attention to all aspects of these challenges is very important for design of an

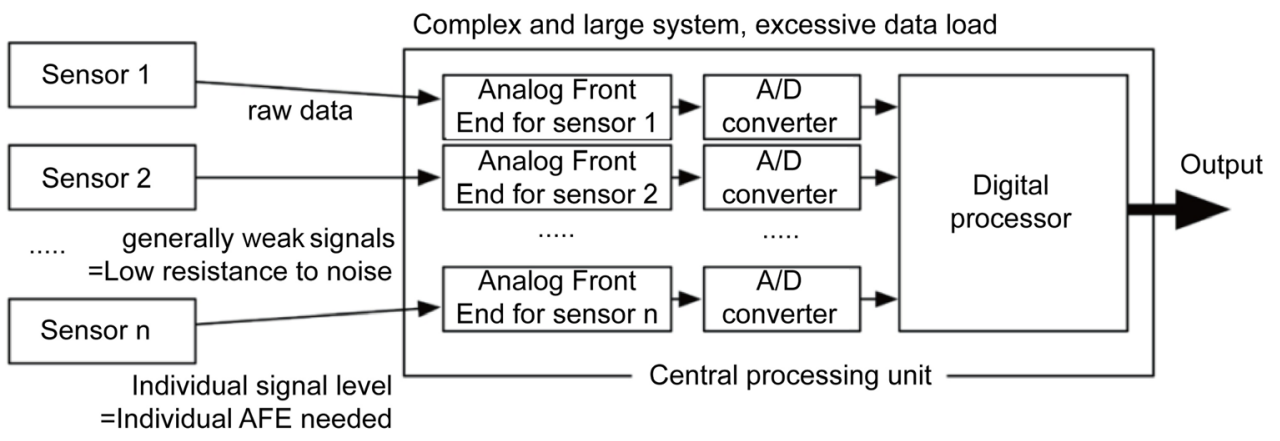

(a)

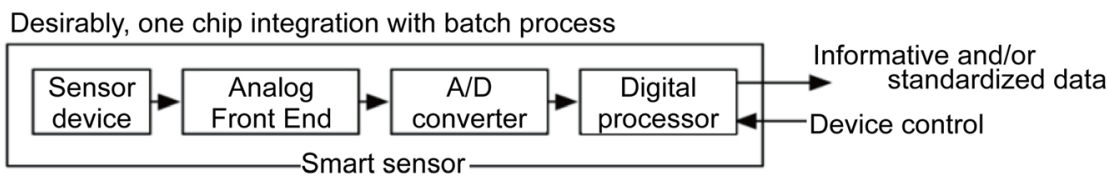

(b)

Figure 3. Signal processing unit for WSNs [22] can also be used in UASNs. Parts (a) and (b) are related to systems with centeralized and distributed processing, respectively. 


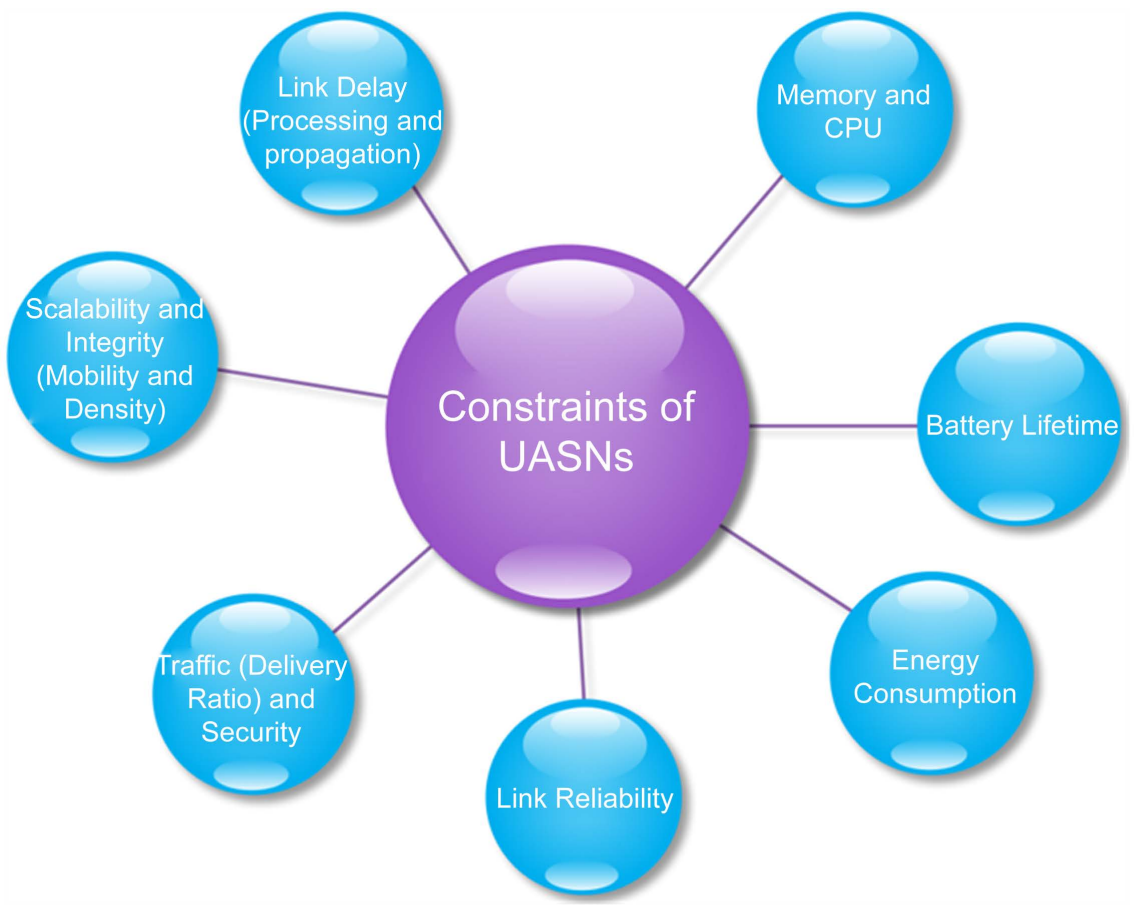

Figure 4. A general overview on UASNs' constraints for designing the network protocols; percentage of importance of these mentioned cases in different applications may be various; however, the most important cases are often energy consumption and traffic performance.

UASN. For more details and description in this respect, refer to [12].

\section{Conclusion}

In this paper, we reviewed the features and challenges of the underwater acoustic links in order to apply in underwater sensor networks. Generally, main idea of this survey is creation of a perception of underwater acoustic sensor networks' challenges. The discussed items contained PHY layer constraint, MAC and routing design, and new topics regarding signal processing of UASNs. We find out that all of these challenges create networking complexity; therefore, attention to these challenges is an essential condition while designing the efficient network protocols.

\section{References}

[1] Stojanovic, M. (2006) On the Relationship between Capacity and Distance in an Underwater Acoustic Channel. ACM International Workshop on Underwater Networks, Los Angeles, 25 September 2006, 41-47. https://doi.org/10.1145/1161039.1161049

[2] Mackenzie, K.V. (1981) Nine-Term Equation for Sound Velocity in the Oceans. Journal of Acoustics Society of America, 70, 807-812. https://doi.org/10.1121/1.386920

[3] Yu, H., Yao, N. and Liu, J. (2014) An Adaptive Routing Protocol in Underwater Sparse Acoustic Sensor Networks. Ad Hoc Networks, 34, 121-143.

[4] Esfandiar, P. (2011) Improving VBF Protocol by Using a Nature-Inspired Algo- 
rithm in Underwater Sensor Networks (UWSNs). Thesis, Shiraz University, Shiraz.

[5] Akyildiz, I.F., Pompili, D. and Melodia, T. (2005) Underwater Acoustic Sensor Networks: Research Challenges. Ad Hoc Networks, 3, 257-279.

https://doi.org/10.1016/j.adhoc.2005.01.004

[6] Khosravi, M.R., Basri, H., Khosravi, A. and Rostami, H. (2015) Energy Efficient Spherical Divisions for VBF-Based Routing in Dense UWSNs. KBEI 2015, Tehran, 5-6 November 2015, 961-965. https://doi.org/10.1109/KBEI.2015.7436174

[7] Heidemann, J., Stojanovic, M. and Zorzi, M. (2012) Underwater Sensor Networks: Applications, Advances and Challenges. Philosophical Transactions of the Royal Society A, 370, 158-175. https://doi.org/10.1098/rsta.2011.0214

[8] Forouzan, B.A. (2007) Data Communications and Networking. 4th Edition, McGraw-Hill, New York.

[9] Tanenbaum, A.S. (2011) Computer Networks. 5th Edition, Prentice Hall, Upper Saddle River.

[10] Bai, W., Wang, H., Shen, X., Zhao, R. and Zhang, Y. (2016) Minimum Delay Multipath Routing Based on TDMA for Underwater Acoustic Sensor Network. International Journal of Distributed Sensor Networks, 2016, Article ID: 1394340. https://doi.org/10.1155/2016/1394340

[11] Wu, H., Chen, M. and Guan, X. (2012) A Network Coding Based Routing Protocol for Underwater Sensor Networks. Sensors, 12, 4559-4577. https://doi.org/10.3390/s120404559

[12] Khosravi, M.R. (2015) Routing Analysis and Evaluation for Underwater Acoustic Sensor Networks. Thesis, Persian Gulf University, Bushehr.

[13] Wahid, A. and Dongkyun, K. (2010) Analyzing Routing Protocols for Underwater Wireless Sensor Networks. International Journal of Communication Networks and Information Security, 2, 253-261.

[14] Wahid, A. and Dongkyun K. (2012) An Energy Efficient Localization-Free Routing Protocol for Underwater Wireless Sensor Networks. International Journal of Distributed Sensor Networks. https://doi.org/10.1155/2012/307246

[15] Diao, B., Xu, Y., An, Z., Wang, F. and Li, C. (2015) Improving Both Energy and Time Efficiency of Depth-Based Routing for Underwater Sensor Networks. International Journal of Distributed Sensor Networks, 2015, Article ID: 781932. https://doi.org/10.1155/2015/781932

[16] Khosravi, M.R., Basri, H. and Rostami, H. (2016) A Solution for Scalable Routing in Depth Divisions-Based DUSNs via Adding a Scalable Parameter to Control Depth Clusters: Creating an Energy Efficient and Low Delay NI-Independent Communication Protocol. Journal of Computer and Communications, 4, 55-61. https://doi.org/10.4236/jcc.2016.47008

[17] Xie, P., Zhou, Z., Nicolaou, N., See, A., Cui, J. and Shi, Z. (2010) Efficient Vector-Based Forwarding for Underwater Sensor Networks. EURASIP Journal on Wireless Communications and Networking, 2010, Article ID: 195910. https://doi.org/10.1155/2010/195910

[18] Yan, H., Shi, Z. and Cui, J. (2008) DBR: Depth-Based Routing for Underwater Sensor Networks. Proceedings of the 7 th International IFIP-TC6 Networking Conference on Ad Hoc and Sensor Networks, Wireless Networks, Next Generation Internet, Singapore, 5-9 May 2008, 72-86.

[19] Nicolaou, N., See, A., Xie, P., Cui, J. and Maggiorini, D. (2007) Improving the Robustness of Location-Based Routing for Underwater Sensor Networks. OCEANS 2007, Aberdeen, 18-21 June 2007, 1-6. 
[20] Khosravi, M.R., Basri, H. and Rostami, H. (2015) Improvement of Energy Consumption in Dense Underwater Sensor Networks. IT 2015, Tehran, 1-9.

[21] Khosravi, M.R., Basri, H. and Rostami, H. (2016) Energy Efficient Random Cooperations for VBF-Based Routing in Dense UWSNs. ICNRAECE 2016, Tehran.

[22] Maenaka, K. (2016) Sensor in Network (1): Origin of Sensor Intelligence. Sensors and Materials, 28, 745-748.

[23] Halloush, M., Al-Zoubi, H.R., Al-Qudah, Z. and Alkofahi, O. (2013) The Performance of MANET Routing Protocols for Scalable Video Communication. Communications and Network, 5, 119-125. https://doi.org/10.4236/cn.2013.52012

[24] Carvalho, T., Júnior, J.J. and Francês, R. (2016) A New Cross-Layer Routing with Energy Awareness in Hybrid Mobile Ad Hoc Networks: A Fuzzy-Based Mechanism. Simulation Modelling Practice and Theory, 63, 1-22. https://doi.org/10.1016/j.simpat.2016.02.003

[25] Wang, H. (2013) Communication-Resource-Aware Adaptive Watermarking for Multimedia Authentication in Wireless Multimedia Sensor Networks. The Journal of Supercomputing, 64, 883-897. https://doi.org/10.1007/s11227-010-0500-5

[26] Haghighat, M.B.A., Aghagolzadeh, A. and Seyedarabi, H. (2011) Multi-Focus Image Fusion for Visual Sensor Networks in DCT Domain. Computers and Electrical Engineering, 37, 789-797. https://doi.org/10.1016/j.compeleceng.2011.04.016

[27] Phamila, Y.A.V. and Amutha, R. (2014) Discrete Cosine Transform Based Fusion of Multi-Focus Images for Visual Sensor Networks. Signal Processing, 95, 161-170. https://doi.org/10.1016/j.sigpro.2013.09.001

[28] Khosravi, M.R., Keshavarz, A., Rostami, H. and Mansouri, S. (2015) Statistical Image Fusion for HR Band Colorization in Landsat Sensors. CSICC 2015, Mashhad, 245-250.

[29] Khosravi, M.R., Salari, S.R. and Rostami, H. (2015) Analysis of Modeling Error in Digital Image Spatial Estimation. IT2015, Tehran.

[30] Khosravi, M.R., Salari, S.R. and Rostami, H. Analysis of Modeling Error in Digital Image Spatial Estimation Based on LMMSE Algorithm. Journal of New Ideas on Science and Technology. (In Press)

[31] Khosravi, M.R., Khosravi, A., Shadloo, M. and Keshavarz, A. (2015) A Novel Fake Color Scheme Based on Depth Protection for MR Passive/Optical Sensors. KBEI 2015, Tehran, 5-6 November 2015, 362-367. https://doi.org/10.1109/KBEI.2015.7436072

[32] Khosravi, M.R. and Rostami, H. (2016) A New Statistical Technique for Interpolation of Landsat Images. ICAUCAE 2016, Tehran, 7 March 2016, 1-3.

[33] Khosravi, M.R. and Rostami, H. (2016) Improving the Binary Watermark-Based Data Hiding Scheme in Remote Sensing Images. ICAUCAE 2016, Tehran, 7 March 2016.

[34] Khosravi, M.R. and Moghimi, M.K. (2016) Theoretical Evaluation of Li et al.'s Approach for Improving a Binary Watermark-Based Scheme in Remote Sensing Data Communications. Majlesi Journal of Telecommunication Devices, 5, 151-153.

[35] Khosravi, M.R., Mansouri, S., Keshavarz, A. and Rostami, H. (2015) MRF-Based Multispectral Image Fusion Using an Adaptive Approach Based on Edge-Guided Interpolation.

[36] Salari, R., Mohseni, A., Khosravi, M.R. and Rostami, H. (2015) Evaluation of Statistical and Nonlinear Adaptive Filters Performance for Noise Reduction of SAR Images. IT 2015, Tehran. 
[37] Moghimi, M.K. and Pourghassem, H. (2015) Shadow Detection Based on Combinations of Hessenberg Decomposition and Principal Component Analysis in Surveillance Applications. IETE Journal of Research, 61, 269-284. https://doi.org/10.1080/03772063.2015.1018848

[38] Moghimi, M.K. and Pourghassem, H. (2014) Shadow Detection Based on Combinations of HSV Color Space and Orthogonal Transformation in Surveillance Videos. Iranian Conference on Intelligent Systems, Bam, 4-6 February 2014, 1-6. https://doi.org/10.1109/IranianCIS.2014.6802548

[39] Moghimi, M.K. and Moghimi, M.M. (2014) Vehicle Detection Based on Viola Jones Algorithm in Surveillance Videos. 6th Iranian Conference on Electrical and Electronics Engineering, Gonabad, 19-21 August 2014.

[40] Moghimi, M.K. and Pourghassem, H. (2016) Shadow Detection Based on Combinations of HSV Color Space and Principal Component Analysis in Surveillance Applications. Journal of Electronics Industries, 7, 15-27.

[41] Khosravi, M.R., Basri, H. and Rostami, H. (2015) Routing with Using Vector-Based Forwarding in Underwater Wireless Sensor Networks. IT 2015, Tehran.

[42] Khayat, A., Monemi, M. and Moghimi, M.K. (2016) Quality of Service Improvement by Distributed Control Algorithms in Code Division Multiple Access Networks. ICNRAECE 2016, Tehran.

[43] Zahedi, A. (2015) Audio Coding in Wireless Acoustic Sensor Networks. Signal Processing, 107, 141-152. https://doi.org/10.1016/j.sigpro.2014.07.021

[44] Melodia, T. (2013) Advances in Underwater Acoustic Networking. In: Basagni, S., Conti, M., Giordano, S. and Stojmenovic, I., Eds., Mobile Ad Hoc Networking. Cutting Edge Directions, Chapter 23, John Wiley and Sons, Hoboken.

[45] Tu, K., Duman, T.M., Stojanovic, M. and Proakis, J.G. (2011) OFDMA for Underwater Acoustic Communications. 47 th Annual Allerton Conference, Monticello, 28-30 September 2011, 633-638. https://doi.org/10.1109/allerton.2011.6120227

\section{Submit or recommend next manuscript to SCIRP and we will provide best service for you:}

Accepting pre-submission inquiries through Email, Facebook, LinkedIn, Twitter, etc. A wide selection of journals (inclusive of 9 subjects, more than 200 journals)

Providing 24-hour high-quality service

User-friendly online submission system

Fair and swift peer-review system

Efficient typesetting and proofreading procedure

Display of the result of downloads and visits, as well as the number of cited articles

Maximum dissemination of your research work

Submit your manuscript at: http://papersubmission.scirp.org/

Or contact jcc@scirp.org 